\title{
Diagnostic value of detection of serum $\beta$-HCG and CT-IgG combined with transvaginal ultrasonography in early tubal pregnancy
}

\author{
HONGYAN XIN ${ }^{1}$, WENLIAN LIU ${ }^{2}$ and PING LI ${ }^{2}$ \\ Departments of ${ }^{1}$ Ultrasonography and ${ }^{2}$ Obstetrics and Gynecology, \\ Linyi People's Hospital, Linyi, Shandong 276000, P.R. China
}

Received October 21, 2017; Accepted April 23, 2018

DOI: 10.3892/etm.2018.6166

\begin{abstract}
The diagnostic value of detection of serum $\beta$-human chorionic gonadotropin $(\beta-\mathrm{HCG})$ and Chlamydia trachomatis immunoglobulin G (CT-IgG) combined with transvaginal ultrasonography in early tubal pregnancy was investigated. A total of 55 patients with early tubal pregnancy were selected as the tubal pregnancy group, while 55 subjects of normal intrauterine pregnancy were enrolled as the intrauterine pregnancy group. Transvaginal ultrasonography and quantitative detection of serum $\beta$-HCG and CT-IgG were performed for all patients, and the clinical examination results were analyzed and compared. The endometrial thickness and serum $\beta-\mathrm{HCG}$ level of patients with early tubal pregnancy were significantly lower than those of women with intrauterine pregnancy $(6.7 \pm 1.5$ vs. $11.6 \pm 1.2 \mathrm{~mm} ; 776 \pm 109$ vs. $5,598 \pm 187 \mathrm{U} / \mathrm{l})$, and the differences were statistically significant $(\mathrm{p}<0.01)$; the serum CT-IgG antibody positive rate of patients in tubal pregnancy group $(49.1 \%)$ was significantly higher than that in intrauterine pregnancy group $(12.7 \%)(\mathrm{p}<0.01)$; the serum CT-IgG antibody positive rates of patients with degree I, II and III of pelvic adhesion intubal pregnancy group were 28.6, 75.0 and $81.8 \%$, respectively; the more severe the pelvic adhesion was, the higher the CT-IgG positive rate would be. The diagnostic coincidence rate of combined detection was significantly higher than that of single detection of serum $\beta$-HCG, progesterone and endometrial thickness. The detection of serum $\beta$-HCG and CT-IgG combined with transvaginal ultrasonography can diagnose the early tubal pregnancy soonest possible, and help choose the appropriate therapeutic methods depending on the situation to reduce the tubal damage of patients, so as to
\end{abstract}

Correspondence to: Dr Ping Li, Department of Obstetrics and Gynecology, Linyi People's Hospital, 27 Jiefang Road, Linyi, Shandong 276000, P.R. China

E-mail: liping7229@163.com

Key words: early tubal pregnancy, transvaginal ultrasonography, serum $\beta$-human chorionic gonadotropin, Chlamydia trachomatis immunoglobulin $\mathrm{G}$ provide a reliable basis for the diagnosis, treatment and prognosis, and it has important clinical application value.

\section{Introduction}

The implantation site of the fertilized egg in the fallopian tube, is known as tubal pregnancy and is the most common ectopic pregnancy (1). The early diagnostic methods of tubal pregnancy include transvaginal ultrasonography, laparoscopy, detection of progesterone, serum $\beta$-human chorionic gonadotropin $(\beta-\mathrm{HCG})$ and other biochemical indexes. The study of the correlation between Chlamydia trachomatis immunoglobulin $\mathrm{G}$ (CT-IgG) antibody and salpingitis, tubal pregnancy and tubal infertility has been reported $(2,3)$. The clinical manifestations of early tubal pregnancy are not specific and similar to the symptoms of early intrauterine pregnancy and abortion, and in addition to the individual differences of pregnant women, sometimes the single detection method is not enough to diagnose tubal pregnancy. Life will be threatened once the rupture or abortion occurs $(4,5)$.

In this study, tubal pregnancy was diagnosed via the detection of serum $\beta$-HCG and CT-IgG combined with transvaginal ultrasonography, to explore a safe, effective and highly accurate diagnostic scheme to guide the clinical practice.

\section{Patients and methods}

Patients. A total of 55 patients with early tubal pregnancy treated in Linyi People's Hospital (Linyi, China) from September 2015 to September 2016 were collected as the tubal pregnancy group, while 55 subjects of early intrauterine pregnancy were collected as the intrauterine pregnancy group. Before the study, patients signed the informed consent. The general data, such as age, pregnancy times and past medical history, had no statistically significant differences between the two groups and were comparable. The Ethics Committee of Linyi People's Hospital approved this study [201502-007]. Signed informed consents were obtained from all the patients or guardians.

Inclusion criteria and exclusion criteria. Inclusion criteria were: i) A slightly larger uterus and an appendage or thickening of the uterus with obvious pain in gynecologic examination; 
Table I. Comparisons of general clinical data between tubal and intrauterine pregnancy group.

\begin{tabular}{|c|c|c|c|c|c|c|}
\hline $\begin{array}{l}\text { Pregnancy } \\
\text { Group }\end{array}$ & No. & Age & $\begin{array}{l}\text { Pregnant } \\
\text { times }\end{array}$ & $\begin{array}{l}\text { History of pelvic } \\
\text { inflammation }\end{array}$ & $\begin{array}{c}\text { History of } \\
\text { spontaneous abortion }\end{array}$ & $\begin{array}{c}\text { History of } \\
\text { implanting IUD }\end{array}$ \\
\hline Tubal & 55 & $25.2 \pm 3.6$ & $1.4 \pm 0.1$ & $14(25.5 \%)$ & $4(7.2 \%)$ & $8(14.5 \%)$ \\
\hline Intrauterine & 55 & $25.9 \pm 4.1$ & $1.5 \pm 0.5$ & $11(20.0 \%)$ & $3(5.5 \%)$ & $7(12.7 \%)$ \\
\hline P-value & & 0.563 & 0.472 & 0.338 & 0.415 & 0.511 \\
\hline
\end{tabular}

In the comparisons between the two groups, $\mathrm{p}>0.05$. IUD, intrauterine device.

Table II. Comparison of serum $\beta$-HCG level between tubal and intrauterine pregnancy group.

\begin{tabular}{lcccc}
\hline & & \multicolumn{3}{c}{$\beta$-HCG (U/l) } \\
\cline { 3 - 5 } Group & No. & On admission & $48 \mathrm{~h}$ & $\mathrm{t}$ \\
\hline Tubal pregnancy group & 55 & $776 \pm 109$ & $758 \pm 111$ & 0.707 \\
Intrauterine pregnancy group & 55 & $5,598 \pm 187$ & $10,997 \pm 1,798$ & 19.898 \\
$\mathrm{t}$ & & 150.166 & 45.733 & 0.008 \\
P-value & & $<0.001$ & $<0.001$ & \\
\hline
\end{tabular}

$\beta$-HCG, $\beta$-human chorionic gonadotropin.

ii) a history of menopause; iii) $\beta-\mathrm{HCG}$ test results were positive; and iv) there was no obvious echo in the womb of the patient's uterus, and the echo of abnormal mass was found in the accessory area of the para uteri.

Exclusion criteria were: Ultrasound examination shows the echo of the intrauterine gestation sac, which shows the yolk sac, the germ, the intrauterine pregnancy of the primitive heart tube pulsation.

Detection protocols. Transvaginal ultrasonography was performed using the LOGIQ-3 digital color Doppler ultrasound diagnostic apparatus (General Electric, Schenectady, NY, USA). Fasting blood $(2 \mathrm{ml})$ was drawn from the two groups of subjects in the morning for the detection of IgG. Serum CT-IgG was detected using the enzyme-linked immunosorbent assay (ELISA) kit (Biovision, Beijing, China). Serum $\beta$-HCG was detected using the ELECSYS 2010 electrochemiluminescence full automated immunoassay analyzer (Roche Diagnostics, Basel, Switzerland).

Observation indexes. The detection results of serum $\beta-\mathrm{HCG}$ and CT-IgG in subjects were observed, and the endometrial thickness was detected via ultrasound. Levels of serum $\beta$-HCG in subjects were detected again after $48 \mathrm{~h}$, and whether the chronic pelvic adhesion existed and its degree in patients with tubal pregnancy were detected during operation. Degree I: No adhesion or mild membranous adhesion; degree II: Adhesion easy to be separated; degree III: Severe adhesion that cannot be separated. The diagnostic coincidence rate was based on the mean values of the three kinds of detection methods of normal pregnancy. Endometrial thickness $<11.2 \mathrm{~mm}$ and $\beta$-HCG level $<1,500 \mathrm{U} / 1$ may indicate early tubal pregnancy.
Statistical analysis. Statistical Product and Service Solutions (SPSS) 19.0 software (IBM Corp., Armonk, NY, USA) was used for the statistical treatment and analysis of research data. Measurement data are presented as mean \pm standard deviation. Comparison between groups was done using one-way ANOVA test followed by post hoc test (Least Significant Difference). Chi-square test was used for the comparison of enumeration data. $\mathrm{P}<0.05$ indicates that the difference is statistically significant.

\section{Results}

Comparison of clinical data. Basic data for the patients in tubal pregnancy and intrauterine pregnancy groups are shown in Table I. There was no significant difference in age, pregnancy times, history of pelvic inflammation, history of spontaneous abortion and history of implanting intrauterine device (IUD) between the two groups ( $p>0.05$ ).

Comparison of serum $\beta-H C G$ and CT-IgG between tubal and intrauterine pregnancy group. The levels of serum $\beta-\mathrm{HCG}$ and CT-IgG of patients with early tubal pregnancy on the admission day and after $48 \mathrm{~h}$ were significantly lower than those in women with intrauterine pregnancy $(\mathrm{p}<0.01)$ (Table II). The level of serum $\beta$-HCG in women with intrauterine pregnancy after $48 \mathrm{~h}$ was significantly higher than that on the admission day $(\mathrm{p}<0.01)$. There was no statistically significant difference in the comparison of serum $\beta$-HCG level in patients with early tubal pregnancy on the admission day and after $48 \mathrm{~h}$ ( $\mathrm{p}>0.05)$. The serum CT-IgG antibody-positive rate of patients in tubal pregnancy group $(49.1 \%)$ was significantly higher than that in intrauterine pregnancy group $(12.7 \%)(\mathrm{p}<0.01)$ (Fig. 1). that in intrauterine pregnancy group $(12.7 \%)(\mathrm{p}<0.01)$ (Fig. 1). 
Table III. Comparison of transvaginal ultrasound examination results between tubal and intrauterine pregnancy group.

\begin{tabular}{lcccc}
\hline & & & Transvaginal ultrasonography \\
\cline { 3 - 5 } Group & No. & $\begin{array}{c}\text { Endometrial } \\
\text { thickness }(\mathrm{mm})\end{array}$ & $\begin{array}{c}\text { Mass size in } \\
\text { adnexa area }\left(\mathrm{cm}^{2}\right)\end{array}$ & $\begin{array}{c}\text { Pelvic } \\
\text { effusion }(\mathrm{cm})\end{array}$ \\
\hline Tubal pregnancy group & 55 & $6.9 \pm 1.7$ & $60.5 \pm 46.2$ & $2.4 \pm 1.2$ \\
Intrauterine pregnancy group & 55 & $11.6 \pm 1.2$ & $34.2 \pm 25.7$ & $2.0 \pm 1.4$ \\
P-value & & 0.003 & 0.002 & 0.368 \\
\hline
\end{tabular}

Table IV. Comparison of diagnostic coincidence rates of different detection methods between tubal and intrauterine pregnancy group.

\begin{tabular}{lccccc}
\hline Group & No. & $\beta-H C G$ & CT-IgG & Endometrial thickness & Combined detection \\
\hline Tubal pregnancy group $^{\text {P-value }}$ & 55 & $28(50.9 \%)$ & $41(74.5 \%)$ & $45(81.8 \%)$ & $53(96.4 \%)$ \\
P-value $^{\text {b }}$ & & 0.0152 & 0.0454 & & \\
Intrauterine pregnancy group $^{\text {P-value }}$ & 55 & $34(61.8 \%)$ & $43(78.2 \%)$ & $49(89.1 \%)$ & $54(98.2 \%)$ \\
P-value $^{\text {b }}$ & & 0.0207 & 0.0416 & & \\
\hline
\end{tabular}

${ }^{a}$ Compared with endometrial thickness; ${ }^{b}$ compared with combined detection. $\beta$-HCG, $\beta$-human chorionic gonadotropin; CT-IgG, Chlamydia trachomatis immunoglobulin G.

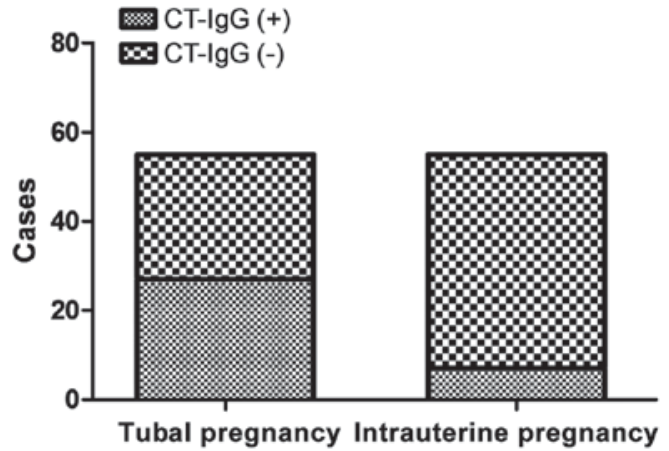

Figure 1. CT-IgG positive cases in tubal and intrauterine pregnancy groups: CT-IgG-positive rate in tubal pregnancy was significantly higher than that of the intrauterine pregnancy group $(\mathrm{p}<0.01)$. CT-IgG, Chlamydia trachomatis immunoglobulin G.

Human monoclonal CT-IgG antibody (dilution: 1:2,000; cat. no. ab108720) was purchased from Abcam (Cambridge, MA, USA).

Comparison of endometrial thickness and mass size in adnexa area between tubal and intrauterine pregnancy groups. Endometrial thickness in patients with early tubal pregnancy on the admission day and after $48 \mathrm{~h}$ was significantly lower than those in women with intrauterine pregnancy $(\mathrm{p}<0.01)$. Mass size in adnexa area of patients with early tubal pregnancy on the admission day and after $48 \mathrm{~h}$ was significantly bigger than those in women with intrauterine pregnancy $(\mathrm{p}<0.01)$. There was no statistically significant difference in the comparison of

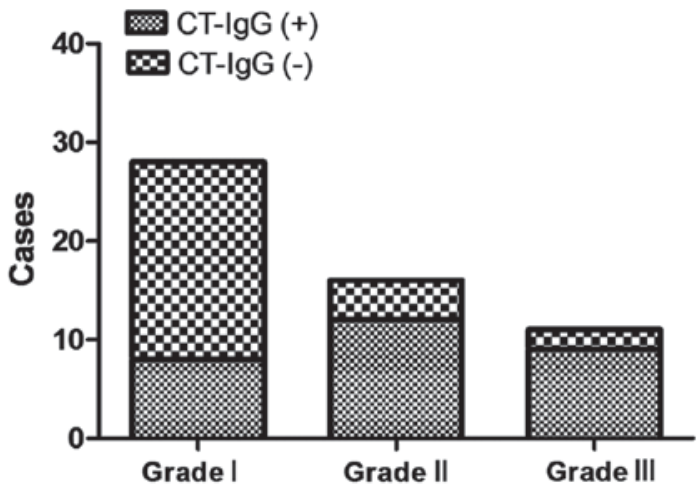

Figure 2. Association between pelvic adhesion grading and CT-IgG positive rates: the more severe the pelvic adhesion is, the higher the CT-IgG positive rate will be $(\mathrm{p}<0.01)$. CT-IgG, Chlamydia trachomatis immunoglobulin $\mathrm{G}$.

pelvic effusion between the two groups on the admission day or after $48 \mathrm{~h}(\mathrm{p}>0.05)$ (Table III).

Pelvic adhesion grading of tubal and intrauterine pregnancy groups. The serum CT-IgG antibody-positive rates of patients with grade I, II and III of pelvic adhesion in tubal pregnancy group were $28.6,75.0$ and $81.8 \%$, respectively. These results suggested that the more severe the pelvic adhesion was, the higher the CT-IgG positive rate would be (Fig. 2).

Comparison of diagnostic results of serum $\beta-H C G, C T-I g G$ and endometrial thickness. The diagnostic coincidence rate of endometrial thickness was higher than that of the detection of 
serum $\beta$-HCG and CT-IgG, and the difference was statistically significant $(\mathrm{p}<0.05)$. The diagnostic coincidence rates of single detection of serum $\beta$-HCG, CT-IgG and transvaginal ultrasonography in the tubal pregnancy and intrauterine pregnancy groups were significantly lower than those of the combined detection $(\mathrm{p}<0.05)$ (Table IV).

\section{Discussion}

Tubal pregnancy is a common acute abdominal disease in gynecology and obstetrics, but its pathogenesis is not clear. The salpingitis, fallopian tube abnormalities, contraception, fertilized egg migration, and endocrine abnormalities may lead to the occurrence of tubal pregnancy (1). The incidence of tubal pregnancy is currently on the increase. However, the number of deaths due to rupture has been reduced rather than increased, and the subsequent fertility function can also be retained as much as possible (1). The main reason is due to the rapid and effective development of early diagnosis and treatment technology.

The determination of HCG is the most commonly used diagnostic method of tubal pregnancy. $\beta-H C G$ is produced by syncytiotrophoblast cells and reflects the activity of villus. Continuous detection of blood $\beta$-HCG can identify intrauterine pregnancy and ectopic pregnancy. It is important for early diagnosis and is also an important monitoring method for conservative treatment of tubal pregnancy (6-8). As the variation range of absolute value of serum $\beta$-HCG is large, it is used to diagnose ectopic pregnancy clinically via monitoring its doubling time. It is reported that the doubling time of serum $\beta$-HCG in patients with ectopic pregnancy is later than that in women with normal intrauterine pregnancy (1.4-2.2 vs. $3-8$ days) (9). The serum $\beta$-HCG level can directly reflect the viability of trophoblasts, and the high $\beta$-HCG level indicates the high proliferation activity of trophoblasts and high invasion into fallopian tube. Dynamic monitoring of serum $\beta$-HCG changes can predict the prognosis of tubal pregnancy. If the serum $\beta-\mathrm{HCG}$ level is $<2,000 \mathrm{IU} / \mathrm{l}$, the drug therapy and non-surgical conservative treatment can be chosen. If the serum $\beta-\mathrm{HCG}$ level continues to rise $>8,000 \mathrm{IU} / 1$, the rupture of tubal pregnancy should be identified and treated by surgery as early as possible (10-12). The results of this study showed that the serum $\beta$-HCG level in women with early tubal pregnancy was significantly lower than that in women with normal intrauterine pregnancy. Moreover, the serum $\beta$-HCG level in women with normal intrauterine pregnancy was obviously increased on the visiting date, suggesting that the serum $\beta$-HCG level in women with normal intrauterine pregnancy can be doubled after $48 \mathrm{~h}$. However, there was no significant change in serum $\beta$-HCG in the early stage of tubal pregnancy, which suggested that the early pregnancy of oviduct is not able to implant in the endometrium, and the decidua reaction cannot be completed normally. Insufficient blood supply affects the development of trophoblastic cells, so the synthesis of $\beta-\mathrm{HCG}$ is reduced.

Within 1-2 weeks after the fertilized eggs are implanted outside the uterine cavity, the serum $\beta$-HCG levels in women with early tubal pregnancy and normal intrauterine pregnancy are similar, so other clinical detection means are often needed to make up for this shortcoming. Due to the high resolution, transvaginal ultrasonography can clearly identify the location of tubal pregnancy and show the small lesions in organs and tissues in pelvic cavity without being affected by the bladder filling and abdominal wall thickness (13). Kirk et al (14) conducted statistical research on transvaginal ultrasonography results of 5,240 menopausal women. The results showed that the positive predictive value and negative predictive value of diagnosis of tubal pregnancy are 96.7 and $99.4 \%$. Ectopic pregnancy is divided into different types according to the symptoms and outcome. No gestational sac but tubal ring sign with specific diagnostic value found in uterine cavity is the important sign of tubal pregnancy, and trophoblastic blood flow can be seen around the tubal ring. In addition, fake gestational sac can occur in ectopic pregnancy due to the hematocele in uterine cavity, and the blood flow resistance is higher because of the blood flow from the endometrial spiral artery, while the trophoblastic blood flow around the true gestational sac is from the original placenta with low resistance $(15,16)$. The results of this study showed that the endometrial thickness in patients with early tubal pregnancy was smaller than that in women with normal intrauterine pregnancy $(\mathrm{p}<0.05)$; the diagnostic coincidence rate of endometrial thickness was higher than that of serum $\beta$-HCG and CT-IgG detection, and the difference was statistically significant $(\mathrm{p}<0.05)$.

One of the main pathogenesis of female urethritis and salpingitis is CT infection. There are often no obvious subjective symptoms in the early stage. CT damages the uterus and adnexa upwards from the infected cervix, leading to tubal pregnancy, tubal infertility and other sequelae $(17,18)$. It is reported that the serum CT-IgG positive antibody can be detected in women with ectopic pregnancy and normal pregnancy, and the rates are 32-71 and 4-39\%, respectively. The relative risk of tubal pregnancy in women with serum CT-IgG positive is 2.4-7.9 (19). Dunne et al (20) studied and suggested that with the decline in CT infection positive rate, the incidence rate of ectopic pregnancy is also rapidly reduced. The results of this study showed that the serum CT-IgG antibody positive rate of patients in tubal pregnancy group was significantly higher than that in intrauterine pregnancy group $(\mathrm{p}<0.01)$. At the same time, it was found that the serum CT-IgG antibody-positive rates of patients with degree I, II and III of pelvic adhesion were $28.6,75.0$ and $81.8 \%$, respectively. The more severe the pelvic adhesion was, the higher the CT-IgG positive rate would be. CT infection often shows the subclinical state with no obvious subjective symptoms. If it is not treated and controlled in time, endometrial and endosalpinx injury is caused, further leading to pelvic adhesion, tubal obstruction and other permanent injuries, which is a basic cause of tubal pregnancy.

In conclusion, the results of the present study have shown that the diagnostic coincidence rates of single detection of serum $\beta$-HCG, CT-IgG and transvaginal ultrasonography in tubal and intrauterine pregnancy group were significantly lower than those of combined detection. Therefore, the detection of serum $\beta$-HCG and CT-IgG combined with transvaginal ultrasonography can improve the diagnostic accuracy of suspected early tubal pregnancy, and provide a reliable basis for clinical treatment and prognosis, which has important application values. However, the sample size of this study is insufficient, and the result is limited. A larger number of samples is needed to confirm the conclusion. 


\section{Acknowledgements}

Not applicable.

\section{Funding}

No funding was received.

\section{Availability of data and materials}

All data generated or analyzed during this study are included in this published article.

\section{Authors' contributions}

HX and PL designed the study, WL performed the ultrasonography, WL and HX collected the data, and WL and PL analyzed the data. HX prepared the manuscript. All authors read and approved the final manuscript.

\section{Ethics approval and consent to participate}

This study was approved by the Ethics Committee of Linyi People's Hospital (Linyi, China). Signed written informed consents were obtained from the patients and/or guardians.

\section{Consent for publication}

Not applicable.

\section{Competing interests}

The authors declare that they have no competing interests.

\section{References}

1. Stulberg DB, Cain LR, Dahlquist I and Lauderdale DS: Ectopic pregnancy rates in the Medicaid population. Am J Obstet Gynecol 208: 274.e1-274.e7, 2013.

2. Ma LK, Cao DY, Yang JX,Liu JT, Shen K and Lang JH: Pregnancy outcome and obstetric management after vaginal radical trachelectomy. Eur Rev Med Pharmacol Sci 18: 3019-3024, 2014.

3. Hoenderboom BM, van Oeffelen AA, van Benthem BH, van Bergen JE, Dukers-Muijrers NH, Götz HM, Hoebe CJ, Hogewoning AA, van der Klis FR, van Baarle D, et al: The Netherlands Chlamydia cohort study (NECCST) protocol to assess the risk of late complications following Chlamydia trachomatis infection in women. BMC Infect Dis 17: 264, 2017.

4. Cain LR and Stulberg D: Ectopic pregnancy rates in a non-Medicaid population are lower than previously reported. Am J Obstet Gynecol 209: 592, 2013.

5. Akaba GO, Agida TE and Onafowokan O: Ectopic pregnancy in Nigeria's federal capital territory: A six year review. Niger J Med 21: 241-245, 2012.
6. Senapati S and Barnhart KT: Biomarkers for ectopic pregnancy and pregnancy of unknown location. Fertil Steril 99: 1107-1116, 2013.

7. Mäkinen J: Current treatment of ectopic pregnancy. Ann Med 31: 197-201, 1999.

8. Taylor AH, Finney M, Lam PM and Konje JC: Modulation of the endocannabinoid system in viable and non-viable first trimester pregnancies by pregnancy-related hormones. Reprod Biol Endocrinol 9: 152, 2011.

9. Gevaert O, De Smet F, Kirk E, Van Calster B, Bourne T, Van Huffel S, Moreau Y, Timmerman D, De Moor B and Condous G: Predicting the outcome of pregnancies of unknown location: Bayesian networks with expert prior information compared to logistic regression. Hum Reprod 21: 1824-1831, 2006.

10. Goksedef BP, Kef S, Akca A, Bayik RN and Cetin A: Risk factors for rupture in tubal ectopic pregnancy: Definition of the clinical findings. Eur J Obstet Gynecol Reprod Biol 154: 96-99, 2011.

11. van Mello NM, Mol F, Ankum WM, Mol BW, van der Veen F and Hajenius PJ: Ectopic pregnancy: How the diagnostic and therapeutic management has changed. Fertil Steril 98: 1066-1073, 2012.

12. van Mello NM, Mol F, Verhoeve HR, van Wely M, Adriaanse AH, Boss EA, Dijkman AB, Bayram N, Emanuel MH, Friederich J, et al: Methotrexate or expectant management in women with an ectopic pregnancy or pregnancy of unknown location and low serum hCG concentrations? A randomized comparison. Hum Reprod 28: 60-67, 2013.

13. Reid S, Casikar I, Barnhart K and Condous G: Serum biomarkers for ectopic pregnancy diagnosis. Expert Opin Med Diagn 6: $153-165,2012$.

14. Kirk E, Papageorghiou AT, Condous G, Tan L, Bora S and Bourne T: The diagnostic effectiveness of an initial transvaginal scan in detecting ectopic pregnancy. Hum Reprod 22: 2824-2828, 2007.

15. Szabó I, Csabay L, Belics Z, Fekete T and Papp Z: Assessment of uterine circulation in ectopic pregnancy by transvaginal color Doppler. Eur J Obstet Gynecol Reprod Biol 106: 203-208, 2003.

16. Thoma ME: Early detection of ectopic pregnancy visualizing the presence of a tubal ring with ultrasonography performed by emergency physicians. Am J Emerg Med 18: 444-448, 2000.

17. Zele-Starcević L, Plecko V, Budimir A and Kalenić S: Choice of antimicrobial drug for infections caused by Chlamydia trachomatis and Chlamydophila pneumoniae. Acta Med Croatica 58: 329-333, 2004 (In Croatian).

18. Stamatopoulos N, Casikar I, Reid S, Roy B, Branley J, Mongelli M and Condous G: Chlamydia trachomatis in fallopian tubes of women undergoing laparoscopy for ectopic pregnancy. Aust N Z J Obstet Gynaecol 52: 377-379, 2012.

19. Li C, Meng CX, Sun LL, Zhao WH, Zhang M, Zhang J and Cheng L: Reduced prevalence of chronic tubal inflammation in tubal pregnancies after levonorgestrel emergency contraception failure. Pharmacoepidemiol Drug Saf 24: 548-554, 2015.

20. Dunne EF, Chapin JB, Rietmeijer CA, Kent CK, Ellen JM, Gaydos CA, Willard NJ, Kohn R, Lloyd L, Thomas S, et al: Rate and predictors of repeat Chlamydia trachomatis infection among men. Sex Transm Dis 35 (Suppl): S40-S44, 2008.

This work is licensed under a Creative Commons Attribution-NonCommercial-NoDerivatives 4.0 International (CC BY-NC-ND 4.0) License. 